\title{
Nutritional Composition and Sensory Quality Evaluation of Injera Prepared from Supplementation of Bread Wheat and Tef Flours
}

\author{
Cherinet Kasahun \\ Food Science and Nutrition Research Directorate, Ethiopian Institute of Agricultural Research, Kulumsa Agricultural Research Center, \\ Assela, Ethiopia
}

Email address:

cherukas05@gmail.com

\section{To cite this article:}

Cherinet Kasahun. Nutritional Composition and Sensory Quality Evaluation of Injera Prepared from Supplementation of Bread Wheat and Tef Flours. World Journal of Food Science and Technology. Vol. 5, No. 3, 2021, pp. 45-49. doi: 10.11648/j.wjfst.20210503.12

Received: June 23, 2021; Accepted: July 14, 2021; Published: July 23, 2021

\begin{abstract}
The increased price of tef, makes tef injera unaffordable for low income households that depend on it as a daily staple food despite tef 's excellent amino acid composition, lysine levels higher than wheat or barley, as very high calcium, phosphorous, iron, copper, aluminum, barium, and thiamine thus there should be a study which fills the gap to optimize the blending of tef with other crops while ensuring nutritional quality, sensory acceptability and cost feasibility to be popularized and consumed. Injera made from whole wheat tef blend can be an important vehicle for conveying nutrition to pregnant women, young females in areas where there is less tendency of consuming wheat and teff blended injera. Red tef grain (Asgori), white teff grain (Quncho) was obtained from DZARC and bread wheat variatty (kingbird) was collected from Kulumsa Agricultural Research center. Proximate composition, mineral and sensory analysis of $100 \%$ tef, $100 \%$ wheat and wheat tef blend (10 to $50 \%$ wheat added to tef) were carried out. $30 \%$ wheat: $70 \%$ tef blended injera proves to be acceptable with respect to $100 \%$ tef injera and it has shown nutritional quality higher value for both iron and zinc content compared to $10 \%$ wheat, $20 \%$ wheat, $40 \%$ wheat and $50 \%$ wheat blended tef injera. Thus, $30 \%$ wheat and $70 \%$ tef blended injera has shown similar sensory quality with respect to overall acceptability to $100 \%$ tef injera and it is also economical important to substitute $30 \%$ of tef flour with $70 \%$ wheat flour in injera preparation.
\end{abstract}

Keywords: Tef, Wheat, Injera, Composite Flour, Nutritional Quality, Sensory Quality

\section{Introduction}

Tef (Eragrostis tef) is a cereal crop widely cultivated in Ethiopia mainly to process its grain flour into injera (a fermented, staple food for the majority of Ethiopians). Making features teff grain is superior as compared to other cereal grains used [8]. Teff injera is known to be high in its micronutrients ( $\mathrm{Fe}, \mathrm{Ca}$ and $\mathrm{Zn}$ ) partly because of agronomic practices used in teff productions in Ethiopia and reduction of mineral inhibitors like phytates on fermentation that enhances bio-availability of minerals [8]. Injera is thin, fermented Ethiopian traditional bread made from flour, water and starter (ersho), which is a fluid saved from previously fermented dough [5].

Teff (Eragrostis teff (Zucc) Trotter) is the most popular grain for making injera, although other grains such as sorghum, maize, barley, wheat and finger millet are sometimes used [3]. Tef [Eragrostis tef (Zucc) Trotter] has the largest share of area $(23.42 \%, 2.6$ million hectares) under cereal cultivation and third (after maize and wheat) in terms of grain production $(18.57 \%, 29.9$ million quintals) in Ethiopia; about two-third of Ethiopian diet consists of injera and it accounts for about two-third of the daily protein intake of the Ethiopian population. The major quality attribute of a good injera is its slightly sour taste, which is due to the acidic (low $\mathrm{pH}$ ) nature of injera [3] Teff is considered to have an excellent amino acid composition, with lysine levels higher than wheat or barley, as well as very high calcium, phosphorous, iron, copper, aluminum, barium, and thiamine [9] Teff flour is higher in ash and lower in protein as compared to wheat flour, teff grain protein ranged from 11.1 to $8.7 \%$ with mean of $10.4 \%$, and the ash content had ranged 
from 3.16 to $1.99 \%$ with mean of $2.45 \%$ [9]. The protein content of wheat grains may vary between $10 \%-18 \%$ of the total dry matter [11]. Whole grains are good sources of insoluble fiber. Arabinoxylan (insoluble type of fibre) is considered to be an optimal substrate for fermentative generation of short-chain fatty acids (SCFAs) - in particular, of butyrate in the colon. Butyrate at high concentrations in the colon is hypothesized to improve bowel health and lower cancer risk by several possible mechanisms. The increasing awareness of the potential benefits of high-fibre diets has promoted a growing interest for the consumption of wholegrain foods [11]. Food products of teff are rich in crude fiber as the whole grain flour of the crop incorporates the bran of the grain. \%e grain of the crop provides relatively higher protein content with an excellent balance and a complete set of essential amino acids [15]. \%e grain is also high in iron content and other minerals such as calcium, copper, and zinc compared to other cereal grains consumed as whole grain flours such as wheat, maize, barley, and sorghum [16]. The chemical composition of teff is not far from those of other cereals, nonetheless the micro-and macronutrients level of grain teff is apparently higher than that of barley, wheat and sorghum [4] and therefore the nutrient composition of grain teff indicates that it has good potential to be used in foods and beverages worldwide.

Whole grain flour is one strategy for the development of healthy food as the consumption of whole grain has been shown to reduce the risk of colorectal cancer, cardiovascular diseases, diabetes and obesity, Injera made from whole teff blend can be an important vehicle for conveying nutrition to pregnant women, young females in areas where there is less tendency of consuming wheat and teff blended injera. Due to the lack of the acceptable organoleptic properties of injera made from wheat and barley, many people do not prefer to eat injera made from other cereals such as wheat and barley [5]. On other hand, increase legumes utilization in Ethiopian for the production of injera in both house and industrial level and used to compact protein and energy malnutrition problem in Ethiopia [13].

Though pure teff injera has enormous health benefits, its cost in the market makes it less available to the poor comminuties. Hence, there should be a study which fills the gap to optimize the blending of teff with other crops while ensuring nutritional quality, sensory acceptability and cost feasibility to be popularized and consumed. According to research report of [12] Supplementations of teff (Eragrostis teff (ZUCC.) Trotter) grain flour to wheat flour at $0,5,10,15$ and $20 \%$ levels on organoleptic and nutritional evaluation of the supplemented bread. Giving increased focus to such underutilized and understudied food crops like teff contributes to food and nutrition security, healthy food availability, income generation for livelihoods of small-scale farmers, and environmental services in the current depleting plant resources and increasing world population [14].

Due to high domestic grain prices, exports of tef from Ethiopia are banned, but some fresh injera made from teff is being exported to the Ethiopian Diaspora and non-Ethiopians.
Although this positively impacts foreign currency earning, it further increases the price of tef, making tef injera unaffordable for low income communities that depend on it as a daily staple food. Therefore, the aim of this study is to prepare nutritionally enriched and socially accepted injera from the blended of wheat and tef composite flours.

\section{Materials and Methods}

\subsection{Study Areas}

The analysis was carried out at Agricultural Quality Research Laboratory (AQRL) and Melkassa Agricultural Research Center Food Science and Nutrition Laboratory, EIAR.

\subsection{Sample Collection and Preparation}

Whole wheat flour prepared for injera making was prepared for further studies like product development/flour formulation, nutritional analysis (proximate analysis) and injera making quality, and sensory quality.

Red tef grain (Asgori tef variety) and white tef grain (Quncho tef variety) were collected from Debre Zeit Agricultural Research Center and the bread wheat (Kingbird variety) was collected from Kulumsa Agricultural Research Center; the grain was then cleaned from dirt by sorting out contaminants such as sands, sticks and leaves, and later was washed and sun dried. The dried tef and wheat was milled using perten laboratory mill tef at $0.5 \mathrm{~mm}$ sieve and wheat at $0.5 \mathrm{~mm}$. The obtained flour was packed in polyethylene bags and stored at room temperature until further analysis.

Formulation of Composite Flour

Bread wheat flour was incorporated tef flour at inclusion level of $10 \%$ interval from 0 to $50 \%$ in the following ratios:

$100 \%$ red or white teff grain flour (control).

$90 \%$ red or white teff grain flour $+10 \%$ bread wheat Flour. $80 \%$ red or white teff grain flour $+20 \%$ bread wheat Flour. $70 \%$ red or white teff grain flour $+30 \%$ bread wheat Flour. $60 \%$ red or white teff grain flour $+40 \%$ bread wheat Flour. $50 \%$ red or white teff grain flour $+50 \%$ bread wheat Flour.

\subsection{Methods}

\subsubsection{Mineral Determination}

About $1 \mathrm{~g}$ of ground sample was ground and put in aluminum dish over night at $105^{\circ} \mathrm{C}$ in an oven, then the sample was Cooled in a desiccator. $0.5 \mathrm{~g}$ of dried sample was weighed and put into a porcelain crucible and put it in a muffle furnace. Then the furnace was switch on and the temperature was increased to $450^{\circ} \mathrm{C}$. The sample was calcinated for 4 hours at this temperature and then the furnace was switch off and allowed to cool inside the closed furnace overnight.

The ashed material was into $200 \mathrm{ml}$ Erlenmeyer flask with

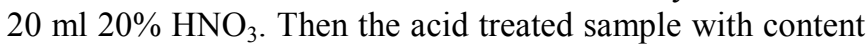
was heated on hot plate to boiling and maintained for 30 minutes with periodic stirring by glass rod, and allowed to cool. The sample was then filtered through a no. 1 filter paper 
into a $100 \mathrm{ml}$ volumetric flask and the contents were washed until $90 \mathrm{ml}$ of the filtrate was collected, and brought to volume with distilled water.

This solution was used for the determination of Iron $(\mathrm{Fe})$ at $259.940 \mathrm{~nm}$ and Zinc (Zn) at $213.857 \mathrm{~nm}$ using $4210 \mathrm{MP}$ - AES (Microwave Plasma - Atomic Emission spectrophotometer).

\subsubsection{Proximate Composition Analysis}

The crude fiber and crude protein content the wheat tef composite flour was analyzed using Near Infrared Spectroscopy (NIRS) at AQRL.

\subsubsection{Sensory Analysis}

The injera for sensory analysis was made based on the method described in [3].

The sensory evaluation of $100 \%$ wheat, $100 \%$ tef and wheat tef blended injera ( $10 \%$ wheat to $50 \%$ wheat) was assessed by 20 semi trained panelists, men and women. All the samples were presented to panelists in a flat tray white color at ambient temperature (about $25^{\circ} \mathrm{C}$ ) 2-4 hours after baking. Since the panelists were not fully-trained, and to make the evaluation process consistent, a simple 5-point hedonic scale was used [7].

\subsection{Data Analysis}

Data obtained from mineral analysis, proximate analysis and sensory evaluation were evaluated using one-way ANOVA and significance of means were declared at $p<0.05$ and mean separation was carried out with Least Significant Difference (LSD) comparison. SPSS software version 22 and Minitab 17 were used for the statistical analysis.

\section{Results and Discussion}

As table 1 below shows the addition of wheat to teff $(10 \%$ to $50 \%$ ) has changed the crude protein and crude fiber content significantly. As the proportion of wheat added to red teff increased the protein content decreased but the fiber content increased. The crude protein content has decreased from 11.88 in $10 \%$ wheat in red teff flour to $9.99 \%$ in $50 \%$ wheat: $50 \%$ red teff flour. Meanwhile, the crude fiber content has increased significantly and wheat white teff composite flour has shown increase in crude fiber content than wheat red teff composite flour.

Tables below have shown that the addition of wheat to teff $(10 \%$ to $50 \%)$ has changed the iron and zinc content significantly. But it is shown in the table that pure red teff flour has higher iron and zinc content than pure 'nech' tef. Teff flour $(7.64 \mathrm{mg} / 100 \mathrm{~g})$ contains significantly more iron than wheat flour $(2.54 \mathrm{mg} / 100 \mathrm{~g})$ [2].

Pure white or red teff flour has shown highest ash content $(2.33 \%)$ than pure wheat flour $(1.33 \%)$ and wheat teff blends. As the addition of wheat to red teff decreases the fat content has shown an increment, fat content of $2.37 \%$ in $30 \%$ wheat: $70 \%$ red teff flour to fat content of $3.08 \%$ in $10 \%$ wheat: $90 \%$ red teff flour. There is significant difference among pure teff flour, pure wheat and wheat teff blends in crude protein, crude fiber, crude fat, ash content but no significant difference in moisture content. 30\% wheat flour blended with $70 \%$ white or red teff flour has shown higher value for both iron and zinc content. Tef grain flour when incorporated in wheat bread is known to improve iron and antioxidant contents of the bread [8].

Table 1. Proximate composition of wheat - teff blended flour.

\begin{tabular}{|c|c|c|c|c|c|c|c|}
\hline Treatment & Crude protein (\%) & Crude Fiber (\%) & Fat $(\%)$ & Ash (\%) & Moisture (\%) & Total Carbohydrate & Energy Kcal/100 g \\
\hline $100 \mathrm{~W}$ & $11.58^{\mathrm{a}}$ & $2.66^{\mathrm{a}}$ & $2.15^{\mathrm{a}^{*}}$ & $1.33^{\mathrm{a}^{*}}$ & $9.995^{\mathrm{a}^{*}}$ & $72.285^{\mathrm{a}}$ & $354.81^{\mathrm{a}}$ \\
\hline $100 \mathrm{NT}$ & $12.78^{\mathrm{b}}$ & $3.0^{\mathrm{b}^{* *}}$ & $1.44^{\mathrm{b}^{*}}$ & $2.33^{\mathrm{b}^{*}}$ & $9.66^{\mathrm{a}^{*}}$ & $70.79^{b}$ & $347.24^{\mathrm{b}}$ \\
\hline 90 NT10W & $11.09^{\mathrm{c}}$ & $3.12^{\mathrm{c}}$ & $2.87^{\mathrm{c}^{*}}$ & $1.67^{\mathrm{c}^{*}}$ & $10.33^{\mathrm{a}^{*}}$ & $70.92^{\mathrm{c}}$ & $353.87^{\mathrm{c}}$ \\
\hline 80NT20W & $11.11^{\mathrm{d}}$ & $3.29^{\mathrm{d}}$ & $2.25^{\mathrm{d}^{*}}$ & $1.33^{\mathrm{d}^{*}}$ & $10^{\mathrm{a}^{*}}$ & $72.02^{\mathrm{d}}$ & $352.77^{d}$ \\
\hline 70NT30W & $11.21^{\mathrm{e}}$ & $3.44^{\mathrm{e}}$ & $1.7^{\mathrm{e}^{*}}$ & $1.67^{\mathrm{e}^{*}}$ & $10^{\mathrm{a}^{*}}$ & $71.98^{\mathrm{e}}$ & $348.06^{\mathrm{e}}$ \\
\hline $60 \mathrm{NT} 40 \mathrm{~W}$ & $11.09^{\mathrm{f}}$ & $3.43^{\mathrm{f}}$ & $2.15^{\mathrm{f}^{*}}$ & $2^{\mathrm{f}^{*}}$ & $10.33^{\mathrm{a}^{*}}$ & $71^{\mathrm{f}}$ & $347.71^{\mathrm{f}}$ \\
\hline $100 \mathrm{KT}$ & $11.2^{\mathrm{a}}$ & $3.1^{\mathrm{a}^{* *}}$ & $2.07^{\mathrm{h}^{*}}$ & $2.33^{\mathrm{h}^{*}}$ & $8.995^{\mathrm{a}^{*}}$ & $71.61^{\mathrm{h}}$ & $349.87^{\mathrm{h}}$ \\
\hline $90 \mathrm{KT} 10 \mathrm{~W}$ & $11.88^{\mathrm{b}}$ & $2.86^{\mathrm{b}}$ & $3.08^{\mathrm{i} *}$ & $2^{\mathrm{i}^{*}}$ & $10.5^{\mathrm{a}^{*}}$ & $69.68^{\mathrm{i}}$ & $353.96^{\mathrm{i}}$ \\
\hline 80KT20W & $11.51^{\mathrm{c}}$ & $2.97^{\mathrm{c}}$ & $2.86^{\mathrm{j}^{*}}$ & $1.67^{j^{*}}$ & $10.33^{\mathrm{a}^{*}}$ & $70.66^{\mathrm{j}}$ & $354.42^{\mathrm{j}}$ \\
\hline $70 \mathrm{KT} 30 \mathrm{~W}$ & $10.46^{\mathrm{d}}$ & $3.22^{\mathrm{d}}$ & $2.37^{\mathrm{k}^{*}}$ & $1.67^{\mathrm{k}^{*}}$ & $10.665^{\mathrm{a}^{*}}$ & $71.62^{\mathrm{k}}$ & $349.63^{k}$ \\
\hline $60 \mathrm{KT} 40 \mathrm{~W}$ & $10.27^{\mathrm{e}}$ & $3.29^{\mathrm{e}}$ & $2.89^{1^{*}}$ & $1.33^{1^{*}}$ & $10.665^{\mathrm{a}^{*}}$ & $71.56^{1}$ & $353.31^{1}$ \\
\hline $50 \mathrm{KT} 50 \mathrm{~W}$ & $9.99^{\mathrm{f}}$ & $3.4^{\mathrm{f}}$ & $0.22^{\mathrm{m}^{*}}$ & $2^{\mathrm{m}^{*}}$ & $10.165^{\mathrm{a}^{*}}$ & $74.23^{\mathrm{m}}$ & $338.84^{\mathrm{m}}$ \\
\hline
\end{tabular}

The means with different letter has significant difference at $\mathrm{p}<0.05$.

Key:

100W $-100 \%$ wheat flour, $100 \mathrm{~W}-100 \%$ wheat flour

$100 \mathrm{NT}-100 \%$ white teff flour, $100 \mathrm{KT}-100 \%$ red teff flour

90NT10W - 90\% white teff: $10 \%$ wheat, $90 \mathrm{KT} 10 \mathrm{~W}-90 \%$ red teff: $10 \%$ wheat flour

80 NT20W - $80 \%$ white teff: $20 \%$ wheat flour, $80 \mathrm{KT} 20 \mathrm{~W}-80 \%$ red teff: $20 \%$ wheat flour

$70 \mathrm{NT} 30 \mathrm{~W}-70 \%$ white teff: $30 \%$ wheat flour, $70 \mathrm{KT} 30 \mathrm{~W}-70 \%$ red teff: $30 \%$ wheat flour $60 \mathrm{NT} 40 \mathrm{~W}-60 \%$ white teff: $40 \%$ wheat flour, $60 \mathrm{KT} 40 \mathrm{~W}-60 \%$ red teff: $40 \%$ wheat flour $50 \mathrm{NT} 50 \mathrm{~W}-50 \%$ white teff: $50 \%$ wheat flour, $50 \mathrm{KT} 50 \mathrm{~W}-50 \%$ red teff: $50 \%$ wheat flour *Teff samples obtained from Debrezeit Agricultural Research Center for fat, ash and moisture analysis were Dukem variety (white teff) and Felagot (red teff)

**Adopted from Nascimento et al., 2018 [10]. 
Table 2. Mineral analysis (Iron and zinc) of teff flour (red and white teff); wheat - teff blended flour.

\begin{tabular}{lll}
\hline Treatments & Iron $(\mathbf{p p m})$ & Zinc $(\mathbf{p p m})$ \\
\hline $100 \%$ red teff & $1.25^{\mathrm{a}}$ & $0.80^{\mathrm{a}}$ \\
$10 \%$ wheat $+90 \%$ red teff & $0.90^{\mathrm{b}}$ & $0.25^{\mathrm{b}}$ \\
$20 \%$ wheat $+80 \%$ red teff & $0.66^{\mathrm{c}}$ & $0.30^{\mathrm{c}}$ \\
$30 \%$ wheat $+70 \%$ red teff & $0.91^{\mathrm{d}}$ & $0.91^{\mathrm{d}}$ \\
$40 \%$ wheat $+60 \%$ red teff & $0.04^{\mathrm{e}}$ & $0.06^{\mathrm{e}}$ \\
$50 \%$ wheat $+50 \%$ red teff & $0.30^{\mathrm{f}}$ & $0.02^{\mathrm{f}}$ \\
$100 \%$ white teff & $0.55^{\mathrm{a}}$ & $0.45^{\mathrm{a}}$ \\
$10 \%$ wheat $+90 \%$ white teff & $0.96^{\mathrm{b}}$ & $0.10^{\mathrm{b}}$ \\
$20 \%$ wheat $+80 \%$ white teff & $1.55^{\mathrm{c}}$ & $0.51^{\mathrm{c}}$ \\
$30 \%$ wheat $+70 \%$ white teff & $0.99^{\mathrm{d}}$ & $0.92^{\mathrm{d}}$ \\
$40 \%$ wheat $+60 \%$ white teff & $1.58^{\mathrm{e}}$ & $0.09^{\mathrm{e}}$ \\
$50 \%$ wheat $+50 \%$ white teff & $0.29^{\mathrm{f}}$ & $0.08^{\mathrm{f}}$ \\
\hline
\end{tabular}

The means with different letter has significant difference at $\mathrm{p}<0.05$.

Table 3 below shows that the sensory evaluation of wheat tef blend injera for eye distribution, color, odor, texture, taste and overall acceptability was assessed. The result has shown that $50 \%$ teff and $50 \%$ wheat blend had significant difference from $100 \%$ teff with respect to eye distribution, color and overall acceptability. Meanwhile, 100\% wheat has shown significant difference from $100 \%$ teff with respect to eye distribution, color, odor, texture, taste and overall acceptability which assures the injera making quality of $100 \%$ teff than $100 \%$ wheat flour.

$20 \%$ wheat, $30 \%$ wheat and $40 \%$ wheat addition to teff flour injera has not shown significant difference from $100 \%$ teff injera in all sensory attributes measured except for significant difference in eye distribution between $100 \%$ teff injera and 30\% wheat: $70 \%$ teff blended injera. The overall acceptability of $100 \%$ teff injera has not shown significant difference $(\mathrm{p} \geq 0.05)$ from 0 verall acceptability of $10 \%$ wheat, $20 \%$ wheat, $30 \%$ wheat and $40 \%$ wheat added teff injera. But $50 \%$ wheat: $50 \%$ teff injera and $100 \%$ wheat injera has shown significant difference from $100 \%$ teff injera. $30 \%$ wheat: $70 \%$ teff blended injera has exhibited a sensory score above the average in a 5-point hedonic scale and nonsignificant $(p \geq 0.05)$ in overall acceptability from $100 \%$ teff injera, which is slightly in agreement with [6] that cassava added to teff up to $30 \%$ scored above average in acceptability tests except color and eye distribution.

Table 3. Sensory analysis of $100 \%$ teff, wheat teff blend and 100\% wheat injera.

\begin{tabular}{|c|c|c|c|c|c|c|c|}
\hline \multicolumn{8}{|c|}{ Wheat-teff flour mixture } \\
\hline Attributes & $100 \%$ teff & $10 \%$ wheat & $20 \%$ wheat & $30 \%$ wheat & $40 \%$ wheat & $50 \%$ wheat & $100 \%$ wheat \\
\hline Eye distribution & $2.15 \pm 1.14^{\mathrm{a}}$ & $2.90 \pm 0.97^{\mathrm{b}}$ & $2.20 \pm 1.01^{\mathrm{a}, \mathrm{c}, \mathrm{d}}$ & $3 \pm 31.08^{\mathrm{b}, \mathrm{c}, \mathrm{d}}$ & $2.30 \pm 1.08^{\mathrm{a}, \mathrm{b}, \mathrm{c}, \mathrm{d}, \mathrm{e}}$ & $3.95 \pm 1.19^{\mathrm{f}}$ & $1.40 \pm 0.68^{\mathrm{g}}$ \\
\hline Color & $2.75 \pm 0.97^{\mathrm{a}, \mathrm{b}, \mathrm{c}, \mathrm{d}, \mathrm{e}}$ & $3.20 \pm 1.06^{\mathrm{a}, \mathrm{b}}$ & $2.50 \pm 1.00^{\mathrm{a}, \mathrm{c}}$ & $3.40 \pm 0.89^{\mathrm{a}, \mathrm{b}, \mathrm{d}, \mathrm{e}, \mathrm{f}}$ & $2.90 \pm 0.85^{\mathrm{a}, \mathrm{b}, \mathrm{c}, \mathrm{d}, \mathrm{e}}$ & $3.80 \pm 1.11^{\mathrm{b}, \mathrm{f}}$ & $2.05 \pm 0.94^{\mathrm{c}, \mathrm{g}}$ \\
\hline Odor & $3.25 \pm 1.02^{\mathrm{a}, \mathrm{b}, \mathrm{c}, \mathrm{d}, \mathrm{e}, \mathrm{f}}$ & $3.35 \pm 0.99^{\mathrm{b}, \mathrm{c}, \mathrm{d}, \mathrm{f}}$ & $2.90 \pm 1.07^{\mathrm{a}, \mathrm{b}, \mathrm{c}, \mathrm{d}}$ & $3.15 \pm 1.04^{\mathrm{a}, \mathrm{b}, \mathrm{c}, \mathrm{d}}$ & $3.25 \pm 1.07^{\mathrm{a}, \mathrm{b}, \mathrm{c}, \mathrm{d}, \mathrm{e}, \mathrm{f}}$ & $3.85 \pm 0.99^{\mathrm{a}, \mathrm{b}, \mathrm{f}}$ & $2.05 \pm 0.83^{\mathrm{g}}$ \\
\hline Texture & $3.05 \pm 1.05^{\mathrm{a}, \mathrm{b}, \mathrm{c}, \mathrm{d}, \mathrm{e}}$ & $2.95 \pm 1.05^{\mathrm{b}, \mathrm{c}, \mathrm{d}, \mathrm{e}}$ & $2.90 \pm 0.91^{\mathrm{a}, \mathrm{b}, \mathrm{c}, \mathrm{d}, \mathrm{e}, \mathrm{g}}$ & $3.25 \pm 1.12^{\mathrm{a}, \mathrm{b}, \mathrm{c}, \mathrm{d}, \mathrm{e}, \mathrm{f}}$ & $3.30 \pm 0.80^{\mathrm{a}, \mathrm{b}, \mathrm{c}, \mathrm{d}, \mathrm{e}, \mathrm{f}}$ & $3.90 \pm 1.12^{\mathrm{a}, \mathrm{b}, \mathrm{c}, \mathrm{f}}$ & $2.25 \pm 1.25^{\mathrm{g}}$ \\
\hline Taste & $3.50 \pm 1.05^{\mathrm{a}}$ & $3.25 \pm 1.07^{\mathrm{a}, \mathrm{b}, \mathrm{c}, \mathrm{d}, \mathrm{e}, \mathrm{f}}$ & $2.90 \pm 0.91^{\mathrm{a}, \mathrm{b}, \mathrm{c}, \mathrm{e}}$ & $3.75 \pm 0.97^{\mathrm{a}, \mathrm{b}, \mathrm{d}, \mathrm{e}, \mathrm{f}}$ & $3.25 \pm 1.02^{\mathrm{a}, \mathrm{b}, \mathrm{c}, \mathrm{d}, \mathrm{e}, \mathrm{f}}$ & $3.80 \pm 0.95^{\mathrm{a}, \mathrm{b}, \mathrm{d}, \mathrm{e}, \mathrm{f}}$ & $1.70 \pm 0.98^{\mathrm{g}}$ \\
\hline
\end{tabular}

\section{Conclusion}

Injera is a widely used food in Ethiopia and improving the nutrient composition help people from nutrient security as well as minimize the price of teff by blending teff with other cereals grains flour such as wheat, maize, and barley. Less expensive and nutrient-dense food formulation is limited in the country. Therefore, this study was conducted to support food and nutrition security problem of the country. In this case, incorporating wheat flour with Teff flour can produce low-cost and nutrient-dense injera to improve food and nutrition security. Considering the continuous increment of teff grain price in the local market, searching for a less expensive cereals grain such as wheat, maize, rice, and sorghum as a substitute to make injera is very important. According to the research finding, using 70\% tef and $30 \%$ wheat to prepare injera will result in injera (flatbread) that is acceptable in its major sensory attributes. The very good sensory result and nutrient content were observed for the treatments $15 \%, 25 \%$, and $30 \%$ of wheat inclusion level this implies that the ratio of blending could be used as a substitute to the teff flour both in the urban and in the rural communities. Moreover, consumers benefited from the use of injera made from these blending ratios of teff and wheat flour due to their enhanced nutritional content as well as the economic advantage due to lower prices of wheat compared to teff.

From this study, it can be concluded that $30 \%$ wheat can be blended with $70 \%$ teff flour and the sensory quality of the $30 \%$ wheat: $70 \%$ teff blended injera proves to be acceptable concerning $100 \%$ teff injera and it has shown that nutritional quality higher value for both iron and zinc content compared to $10 \%$ wheat, $20 \%$ wheat, $40 \%$ wheat and $50 \%$ wheat blended teff injera. Thus, $30 \%$ wheat and $70 \%$ teff blended injera have shown similar sensory quality and it is also economical to substitute $30 \%$ of teff flour with $30 \%$ wheat flour in injera preparation.

\section{Recommendation}

1) Substitute of $30 \%$ tef flour with $70 \%$ wheat flour in injera preparation would be acceptable in nutritional composition and sensory quality acceptance

2) Further research to be conducted on flour functional properties in the future

3) Another study to be carried out on shelf life of injera made from composite flour 


\section{References}

[1] Abera Alemayehu, Milkesab Meskerem, Gebremedhine Hailay (2016). Injera Preparation from Taro (Colocasia esculenta) and Teff (Eragrostis tef) Flour. International Journal of Sciences: Basic and Applied Research. Volume 30, No 1, pp 196-204.

[2] Alaunyte I., Stojceska V., Derbyshire E., Plunkett A. and Ainsworth P. (2010). Iron-rich Teff-grain bread: an opportunity to improve individual's iron status. Proceedings of the Nutrition Society. Over and undernutrition: challenges and approaches.

[3] Ashagrie $Z$ and D. Abate (2013). Improvement of injera shelf life through the use of chemical preservatives. African Journal of Food, Agriculture, Nutrition and Development.

[4] Bultosa G. (2007). Physicochemical characterization of grain and flour in 13 Tef [Eragrostis tef (Zucc.) Trotter] grain varieties.

[5] Daba, Tadessa (2017). Nutritional and socio cultural values of Teff (Eragrostis tef) in Ethiopia. International Journal of Food Science and Nutrition. Volume 2, issue 3. pp. 50-57.

[6] Desalegn B. B., Desta F. T. (2017). Effect of Blending Ratio on Proximate Composition, Physico-Chemical Property, and Sensory Acceptability of Injera Produced from Red Tef (Eragrostis tef) and Cassava (Manihot esculenta). Food Science and Quality Management.

[7] Ghebrehiwot H. M., Shimelis H. A., Kirkman K. P., Laing M. D, and Mabhaudhi T. (2016). Nutritional and Sensory Evaluation of Injera Prepared from tef and Eragrostis curvula (Schrad.) Nees. Flours with Sorghum Blends. Front. Plant Sci. 7: 1059.

[8] Girma Tewdros, Bultosa Geremew and Bussa Negussie (2013). Effect of Grain Tef (Eragrostis tef (Zucc.) Trotter) Flour Substitutions with Flaxseed on Mineral Content, Antioxidant

Activity, Phytic Acid Content and Microbial Quality of Injera. Science, Technology and Arts Research Journal. 2 (3): 51-58.

[9] Mohammed M. I. O., Mustefa A. I., and Osman G. A. M. (2009). Evaluation of wheat breads supplemented with Teff (Eragrostis tef (ZUCC.) Trotter) Grain flour. Australian Journal of Crop Science. (4): 207-212.

[10] Nascimento K. O., Paes S. N. D., Olieviera I. R., Reis I. P., and Augusta I. M. (2018). Teff: Suitability for Different Food Applications and as a Raw Material of Gluten-free, a Literature Review. Journal of Food and Nutrition Research. Vol. 6. No. 2. 74-81.

[11] Šramkováa Z., Gregováb E., and Šturdíka E. (2009). Chemical composition and nutritional quality of wheat grain. Acta Chimica Slovaca. Vol. 2, No. 1. 115-138.

[12] Mariam I. O., Mohammed A., Mustafa., I., and Gammaa A. M Evaluation of wheat breads supplemented with Teff (Eragrostis tef (ZUCC.) Trotter) Grain flour. Australian Journal of Crop Science, Southern Cross Journals@2009 3 (4): 207-212 (2009) www.cropj.com ISSN: 1835-2707.

[13] Lamesgen Y., Solomon A., and Melese T. | (2021). Nutritional composition and sensory quality of injera prepared from tef (Eragrostis tef (Zucc.) Trotter) complemented with lupine (Lupinus spp.), Cogent Food \& Agriculture, 7: 1, 1862469, DOI: $10.1080 / 23311932.2020 .1862469$.

[14] Zhu F.,(2018). "Chemical composition and food uses of teff (Eragrostis tef)," Food Chemistry, vol. 239, pp. 402-415.

[15] Abebe W., Collar C., and Ronda F., (2015). "Impact of variety type and particle size distribution on starch enzymatic hydrolysis and functional properties of tef flours," Carbohydrate Polymers, vol. 115, pp. 260-268.

[16] Campo E., del Arco L., Urtasun L., Oria R., and Ferrer A. (2018)., "Impact of Sourdough on sensory properties and consumers' preference of gluten-free breads enriched with teff. 